\title{
New Zealand Falcon nests suffer lower predation in agricultural habitat than in natural habitat
}

\author{
SARA M. KROSS, PAUL G. McDONALD and XIMENA J. NELSON
}

\section{Summary}

Introduced mammalian predators have been implicated in the majority of avian extinctions on oceanic islands around the globe. Nowhere is this more apparent than in the decimated New Zealand avifauna, where introduced predators remain the primary threat to virtually all surviving endemic species, including the threatened New Zealand Falcon Falco novaeseelandiae. We used remote videography at falcon nests and conducted an artificial nest experiment to compare the rates of predation and responsible predators of falcons nesting in hills against those nesting in nearby commercial vineyards. Overall, $63 \%$ of artificial nests in the hills were predated, compared with $38 \%$ in vineyards. Further, artificial eggs were predated faster in the hills than those placed in vineyards. Video footage revealed that the suite of predators visiting real falcon nests was similar to those identified attacking artificial nests. However, predators differed across habitats, with nests in vineyards being predated mainly by hedgehogs Erinaceus europaeus and Australasian Harriers Circus approximans, whereas nests in the hill environments were mainly attacked by stoats Mustela erminea. These results demonstrate the important implications of habitat type on predation pressure associated with introduced predators. These may well prove a fruitful avenue of management if breeding can be fostered in safer areas, as in the case of this threatened falcon.

\section{Introduction}

Predators can have devastating effects on avian populations, particularly in areas where naïve prey may reside, such as on oceanic islands (Blackburn et al. 2004). For example, predation by feral cats Felis catus has contributed to over $9 \%$ of avian extinctions worldwide (Medina et al. 2011), while invasive rats Rattus spp. have been introduced to over $90 \%$ of the world's islands, where they have had a significant negative impact, leading to the decline or extinction of 60 vertebrate species (Towns et al. 2006). Similarly, hedgehogs Erinaceus europaeus have been implicated in the decline of breeding shorebirds on Scottish islands to which they have been introduced (Jackson et al. 2004). Nowhere is the detrimental impact of these introduced species more apparent than in New Zealand, where exotic mammals have been implicated in the decline of most of the 58 avian species that have become extinct since the arrival of humans.

Primary production regions continue to expand globally, while areas of native vegetation shrink (Foley et al. 2005). Despite this, conservation initiatives for threatened species rarely focus on areas of production, and instead hinge upon regions of remaining native vegetation. Reserves tend to be found in rugged and inaccessible areas of low economic value (Margules and Pressey 2000), whereas production lands tend to be accessible and to have a high availability of resources, both natural and supplemented. There have been calls to extend the conservation mindset into 
our agricultural regions through the use of wildlife-friendly farming practices (MacLeod et al. 2008, Fischer et al. 2011). Similarly, encouraging wildlife to return to production landscapes can improve functional diversity, and has the potential to provide ecosystem services such as pest control (Foley et al. 2005).

Methods aimed at reducing the impact of agricultural activities and increasing the biological value of land being utilised in this manner are being actively sought. One such project is the joint conservation-pest management programme called 'Falcons for Grapes' (FFG), initiated in 2005. Its aim is to establish a population of New Zealand Falcons Falco novaeseelandiae in the vineyarddominated valleys of the country's largest wine-growing region by relocating individual falcons from nearby hills into vineyards (MAF 2009). It has already been demonstrated that falcons can provide ecosystem services for vineyards in the form of pest control (Kross et al. 2012a), and that compared with their counterparts in the surrounding hills, falcons living in vineyards exhibit higher attendance at their nests (Kross et al. 2012b). However, evaluating whether vineyards provide habitat in which predation rates are similar or lower than that of the surrounding hills is critical in assessing the success of this reintroduction programme. This is especially important because in other parts of the world agricultural land has been associated with higher nest predation rates for birds, typically driven by introduced pests (Bayne and Hobson 1997, Vander Haegen et al. 2002).

Typically a ground nesting species, the New Zealand Falcon is the country's only remaining endemic bird of prey and this threatened species is suffering ongoing population declines (Gaze and Hutzler 2004, Miskelly et al. 2008). It has been assumed that introduced mammalian predators have contributed to these declines (Fox 1977, Seaton et al. 2009), although direct evidence for this is limited to a single observation of a feral cat killing a brood (Kross and Nelson 2011; further details herein). Previous studies have used field signs, such as tracks or patterns of feather removal, to attempt to identify the cause of nest failures, although this method is frequently considered unreliable (Pietz and Granfors 200o). Additionally, the assumption that predation is the cause of the disappearance of all eggs and chicks from nests may overlook non-predation events that could impact avian populations, such as egg breakage or nest abandonment (Ratcliffe 1967). Further, as with many raptor species, pairs that suffer early nest failure often go undetected (Newton 1979). Nests with young become easier to detect over time because of increased activity at the nest, audible calls from chicks, and conspicuous faecal build-up (Steenhof and Newton 2007).

In other species, to avoid these issues, artificial nests have been used as approximations of true avian nests that also provide an opportunity to manipulate conditions to better understand the factors influencing nest predation (Wilson et al. 1998, McDonald et al. 2009, Moore and Robinson 2004). Further, artificial nests are particularly attractive when examining threatened species, because they do not involve manipulation of natural nests, and can reach sample sizes that are normally difficult to obtain, whilst controlling for potential biases (Major and Kendall 1996, Wilson et al. 1998, McDonald et al. 2009). As the success of the FFG project lies in the long-term ability of falcons to breed and live within the vineyard landscape, it is critical to determine that nest predation pressures are not greater in the vineyards to which the species is being released in comparison to the unmanaged land in the surrounding hills from which they have been translocated.

\section{Methods}

\section{Study area and species}

Our study was based in Marlborough, the north-eastern province of New Zealand's South Island $\left(41.52^{\circ} \mathrm{S}, 173.872^{\circ} \mathrm{E}\right)$. The region is mainly arid, with a monthly rainfall of 45.4 to $71.6 \mathrm{~mm}$ between October and February. The landscape consists of river valleys dominated by intensively managed viticulture, and unmanaged rugged hills covered by a mix of native and introduced grasses and native shrubs used for non-intensive pastoral grazing (Kross and Nelson 2011). 
The New Zealand Falcon is sexually dimorphic, with females in our study area weighing an average of $531 \mathrm{~g}$ and males weighing $330 \mathrm{~g}$ (Fox 1977). These falcons normally nest under boulders or fallen trees (Fox 1977), but also nest at the base of trees (SMK unpubl. data). The breeding season ranges from September to February, with most egg-laying occurring in October and November and an incubation period of four weeks, after which parents raise chicks for 30-35 days before they fledge (Fox 1977). During this time, falcons are territorial within their estimated $3.8 \mathrm{~km}^{2}$ home range and are highly aggressive towards intruders near their nests (Fox 1977).

\section{Artificial nest experiment}

Nineteen artificial nests were deployed in unmanaged hill habitat ('hill nests') and 21 artificial nests were deployed in managed vineyard habitat ('vineyard nests') between 15 and 30 November 2010. To keep nest sites independent, they were a minimum of $4 \mathrm{~km}$ apart, which is similar to the home range of a likely predator, the stoat Mustela erminea, in New Zealand (Smith et al. 2008). Nests were made by creating a $2 \mathrm{~cm}$ depression in the ground and lining it with nest substrate to mimic a real nest. To minimise variance between sites, we placed all artificial nests at the base of trees.

Yellow microcrystalline wax (Conservation Supplies, Warkworth, NZ) was poured into plaster moulds that had been created from real falcon eggs. Microcrystalline wax was used because it is relatively scent-free, and because it has a high melting point $\left(80^{\circ} \mathrm{C}\right)$ and therefore does not melt in the field. A looped metal wire was inserted into each egg as it was moulded to act as an anchor for pegging eggs to the ground. Eggs were aired outside for two weeks after moulding and then were painted light brown using waterproof exterior house paint. This provided better resolution of any bite marks, and approximated natural falcon egg colouration, at least from a human perspective. Previous studies have shown that the colour of eggs is unlikely to affect predation rates (Major and Kendal 1996), and typical mammalian predators of falcon nests are unlikely to use visual cues as the primary nest detection source (McDonald et al. 2009). Once painted, eggs were aired outside for a further two weeks to ensure that they had a neutral scent prior to being used for this experiment.

Substrate samples were then taken from within and immediately around the nest of a pair of captive New Zealand Falcons and all the wax eggs were placed in a box containing this material for two to three weeks prior to their use. Additional nest substrate was collected from a natural falcon nest and a handful of this was placed under all eggs when they were deployed.

To provide an indication of the temporal predation pressure on nests, we checked nests two weeks after deployment, and if predation was found to have occurred, the nest was removed. We then checked nests again four weeks after deployment to determine the overall proportion of nests that were predated within the typical incubation period of falcons. All predated eggs were compared to a skull collection at the national Te Papa museum, which included potential avian and mammalian predators found in the study area.

\section{Remote videography}

We used remote videography to monitor six nests in the unmanaged hill areas and five nests in vineyards over three breeding seasons to identify any potential predators visiting falcon nests (October 2008-January 2011). The systems worked on a motion-detection threshold, recording at 30 frames per second when activated. Recordings were in colour during the day, and used nearinfrared lighting for black-and-white recordings during darkness (Kross and Nelson 2011). In all cases where an animal came into view near the nest scrape, video was viewed frame-by-frame in order to identify the animal and to analyse its behaviour. We considered all animals that visited falcon nests to be potential predators if there was any evidence in the scientific literature of those animals consuming eggs or chicks of any ground-nesting avian species. Vineyard nests had sporadic mammalian pest control conducted near them, consisting of traps and opportunistic 
shooting, targeting cats, mustelids and hedgehogs. Four of the five falcon nests in the vineyards were also moved into artificial 'nest barrels', consisting of $60 \times 110 \mathrm{~cm}$ plastic drums cut with a $55 \times 30 \mathrm{~cm}$ opening (R. Seaton pers. comm.). These were raised from the ground by the FFG team following hatching to protect chicks from potential predators. Cameras for both ground nests and raised nests recorded behaviour inside and immediately in front of the barrel. For all ground nests, cameras were placed between 0.5 and I $\mathrm{m}$ from the nest scrape on the ground, and were able to capture all behaviour within the scrape and immediately adjacent to it.

\section{Results}

\section{Artificial nest experiment}

Over our four-week study period, a total of 12 out of 19 hill nests were predated $(63.2 \%)$ while 8 out of $21(38.1 \%)$ vineyard nests were predated (Figure 1 ). This effect was not statistically significant $\left(\chi^{2}=2.51, P=0.11\right)$, which is likely a result of our small overall sample size. The rate of predation was significantly faster in hill nests where eight of 19 nests $(42.1 \%)$ were predated after two weeks, compared to three of 21 (I4.3\%) vineyard nests $\left(\chi^{2}=3.87, P<0.05\right)$. Stoats attacked seven of the 19 nests in the hills, but none of the 21 nests placed within vineyards $(P=0.003$, 2-tailed Fisher exact test). Other predatory species did not differ significantly between habitats (Figure I).

\section{Remote videography}

Potential predators were recorded at only one of the five vineyard nests, but no successful predation events occurred. At this nest, our camera revealed a visit and/or an attack by a hedgehog, an Australasian Harrier and a Little Owl Athene noctua.

At hill nests, a number of non-predation events were recorded - all by introduced species during nocturnal hours. At one nest, a red deer Cervus elaphus, and an unidentified species of rat were observed entering the nest scrape on two different nights, but were chased away by the adult falcons. At the same nest, a stoat attacked a 35-day old female falcon chick. The chick survived the attack when the stoat (which was hanging onto the chick's rump) dropped off as the chick flew away. The young falcon was observed again being attacked by a stoat outside the nest scrape in

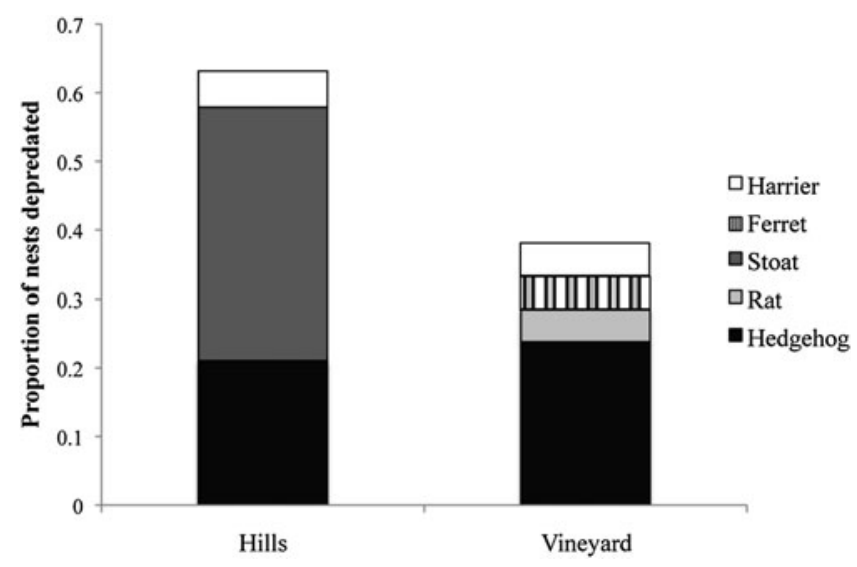

Figure 1. Proportion of artificial New Zealand Falcon Falco novaeseelandiae nests in unmanaged hill habitat versus managed vineyard habitat predated by hedgehogs Erinaceus europaeus, stoats Mustela erminea, ferrets Mustela furo, Norway Rats Rattus norvegicus, and harriers Circus approximans. 
daylight two weeks after fledging. She reacting by performing 'mock attack' play behaviour (often observed between juvenile falcons; Fox 1977) by flying past the stoat, striking it briefly with her talons, and then perching on a nearby rock. The stoat then attempted another attack and the falcon flew away unharmed.

A common brushtail possum Trichosurus vulpecula, was observed on two separate occasions at a different hill nest. On the first occasion a possum entered the nest during the incubating phase and did not attempt to eat any of the three eggs, and was then attacked by the adult female. On the second occasion, a different possum entered the nest the night after the chicks fledged, consuming some food scraps before leaving.

A single successful predation event was recorded at a wild nest, when a feral cat attacked and killed all three chicks over the course of two separate visits. One chick was apparently killed offscreen after disappearing on 15 December 2008, the night that a cat was observed at the nest. The same cat (identified by a distinctive scar on the ear) returned to the nest three days later. Whilst the cat was present, the adult female falcon entered the nest twice, walking in with wings spread, and struck at the cat with her talons. Despite this, the cat captured one of the remaining chicks. Two minutes after this, the last remaining nestling moved away from the cat, walking out of the view of the camera. Just under $2 \mathrm{~h}$ later, after the cat had finished consuming the first chick, it was observed stalking past the camera and 3 min later pulled the remaining chick back into the nest scrape. As the nest was located on a small ledge on a low cliff $(\sim 3 \mathrm{~m}$ diameter $)$, the chick was unlikely to have moved beyond this area, as it was pulled back into the nest by the cat prior to consumption. Still images of predators recorded at falcon nests can be found in Figure $\mathrm{S}_{1}$ in the online Supplementary Materials. In addition to the predation footage, one camera at a vineyard nest recorded a female falcon breaking her own eggs and subsequently eating them.

\section{Discussion}

Our results showed that predators in the hills located and predated nests significantly faster than in vineyards, with nearly twice as many artificial nests predated in the hills after two weeks compared with vineyard nests. We also found that after four weeks, the overall proportion of nests predated in the hills was $63.2 \%$ compared to $38.1 \%$ in the vineyards, although this difference did not reach statistical significance with our sample size. This has important implications for conservation, as our findings suggest that in some cases production landscapes can provide suitable alternative habitat for the recovery of threatened species. Thus far, most studies comparing nest predation in agricultural and natural settings have focused on continental datasets. Our study offers evidence that on an island, where introduced mammals are the main cause of species declines, production land may offer a comparatively safe refuge from primarily introduced predators.

The footage from our remote videography systems provided evidence that the same predators we detected in our artificial nest experiment also targeted real falcon nests, but that actual predation events were lower for the natural nests, as has been suggested by previous artificial nest experiments (Wilson et al. 1998). Through video observations, parental defence of the nest site was clearly implicated as the most likely factor behind this difference, although the interaction with the feral cat also demonstrates that not all predators can be rebuffed by New Zealand Falcons. Furthermore, our footage of the female falcon breaking, and then eating her own eggs provided important evidence that predators are not always responsible for nest failures. Prior to this footage being obtained, missing or damaged eggs were typically assigned to predation events.

Hedgehogs were the main predator that attacked our artificial nests in the vineyards, and the second most important predator of eggs in the hills. Hedgehogs will feed on the eggs of groundnesting avian species, including critically endangered species in New Zealand (Sanders and Maloney 2002). In contrast, stoats were the major predator that visited artificial nests placed in the hills. As particularly voracious predators, stoats have been implicated in the population declines of many New Zealand native birds (McLellan et al. 1996, Whitehead et al. 2008). 
Our data suggest that mustelids may be one of the most dangerous predators for falcons, as they appear to target offspring from eggs through to independence. Cats are also particularly dangerous, as they target not only chicks, but also adult birds (Sanders and Maloney 2002). The primarily herbivorous mammals that we detected (deer and brushtail possum) may only be a rare source of danger for falcons which can be deterred by the presence of adult birds, despite being a threat to birds in other regions (Pietz and Granfors 2000).

Our observations of predation and near-predation events provide evidence that falcon chicks lack viable anti-predator behaviours when faced with mammalian predators. In the case of the feral cat, the final chick to be killed appeared to react to the presence of this predator by hiding within $3 \mathrm{~m}$ of the cat whilst it ate. Similarly, we observed a juvenile falcon seemingly 'playing' with a stoat, only weeks after being attacked by the same type of predator. Even when researchers visit falcon nests, chicks tend to remain completely still, and even let themselves be handled without attempting to escape (Fox 1977, SMK pers. obs.).

Experiments using artificial nests can help to predict the types of predators that are likely to target real nests (Moore and Robinson 2004, Lewis et al. 2009), and our additional direct observations of predators at real falcon nests provides substance to those predictions. These findings elucidate that there are differences of potentially lethal predators in these different habitats. While hedgehogs and raptors were found to predate nests in vineyard sites as frequently as they did in the unmanaged hills, these species are more likely to be deterred by adult falcons than feral cats or than the predominant species detected in the hills, stoats. However, as is the case in all artificial nest studies, these findings should not be relied on to accurately predict actual nest predation rates for New Zealand Falcons. Ongoing monitoring of falcon nests in both habitats is needed, as is a controlled management scheme to ensure that falcon nests in both habitats receive a similar and consistent amount of predator control. Additionally, further investigation into the abundance of potential predators using trapping or tracking tunnels could confirm the predation risk for falcons in agricultural and natural habitats.

As found around the world (Margules and Pressey 2000), most conservation initiatives in New Zealand focus on remaining tracts of native vegetation, despite almost $60 \%$ of the nation's land area being used for production (MacLeod et al. 2008). Globally, primary production regions are expanding, while areas of native vegetation continue to shrink, highlighting the need to extend conservation initiatives into agricultural regions where feasible (Fischer et al. 2011). In some cases, conservation may also benefit agriculture through provisioning of ecosystem services, such as pest control (Kross et al. 2012a). Uniquely, we found that predation rates were likely to be lower in an agricultural setting, which is contrary to findings from overseas studies (Bayne and Hobson 1997; Vander Haegen et al. 2002). This highlights the importance of species-specific assessment of habitat quality, although it is important that studies such as this one are repeated across multiple years and with a larger sample size in the future. Coupled with previous results suggesting that falcons living in vineyards demonstrate higher nest attendance rates and provide more food to their chicks (Kross et al. 2012b), our results indicate that vineyards hold considerable potential for the conservation of New Zealand Falcons, and further support the notion that, pending assessment of their suitability, primary production systems could be used for conservation initiatives of this and similar species.

\section{Supplementary Material}

The supplementary materials for this article can be found at journals.cambridge.org/bci

\section{Acknowledgements}

We thank all of the landowners who gave us access. P. Gaze and P. Bradfield from DoC provided helpful advice, as did D. Smith and G. Stone at Te Papa. N. Hyde at Wingspan Bird of Prey Trust assisted with ferret skull identification and L. Young identified the red deer. R. Brackley assisted 
with artificial nest placement, and a large number of volunteers assisted with remote videography placement. L. Olley gave access to captive falcons and C. Wynn provided the initial egg mould. The FFG project was run by International Wildlife Consultants (UK) Ltd. This research supported by a UC Doctoral Scholarship (SMK), a Brian Mason Scientific and Technical grant (XJN), and a Canon NZ environmental grant (SMK).

\section{References}

Bayne, E. M. and Hobson, K. A. (1997) Comparing the effects of landscape fragmentation by forestry and agriculture on predation of artificial nests. Conserv. Biol. I1: $1418-1429$.

Blackburn, T. M., Cassey, P., Duncan, R. P., Evans, K. L. and Gaston, K. J. (2004) Avian extinction and mammalian introductions on oceanic islands. Science 305: 1955-1958.

Fischer, J., Batary, P., Bawa, K. S., Brussaard, L., Chappell, M. J., Clough, Y., Daily, G. C., Dorrough, J., Hartel, T., Jackson, L. E., Klein, A. M., Kremen, C., Kuemmerle, T., Lindenmayer, D. B., Mooney, H. A., Perfecto, I., Philpott, S. M., Tscharntke, T., Vandermeer, J., Wanger, T. C. and Von Wehrden, H. (2011) Conservation: Limits of land sparing. Science 334: 593-593.

Foley, J. A., Defries, R., Asner, G. P., Barford, C., Bonan, G., Carpenter, S. R., Chapin, F. S., Coe, M. T., Daily, G. C., Gibbs, H. K., Helkowski, J. H., Holloway, T., Howard, E. A., Kucharik, C. J., Monfreda, C., Patz, J. A., Prentice, I. C., Ramankutty, N. and Snyder, P. K. (2005) Global consequences of land use. Science 309: 570-574.

Fox, N. C. (1977) The biology of the New Zealand Falcon (Falco novaeseelandiae Gmelin, 1788). PhD thesis. University of Canterbury, Christchurch.

Gaze, P. and Hutzler, I. (2004) Changes in abundance of New Zealand Falcon (Falco novaeseelandiae) in Marlborough. Notornis 51: 117-119.

Jackson, D. B., Fuller, R. J. and Campbell, S. T. (2004) Long-term population changes among breeding shorebirds in the Outer Hebrides, Scotland, in relation to introduced hedgehogs (Erinaceus europaeus). Biol. Conserv. 117: 151-166.

Kross, S. M. and Nelson, X. J. (2011) A portable low-cost remote videography system for monitoring wildlife. Methods Ecol. Evol. 2: 191-196.
Kross, S. M., Tylianakis, J. M. and Nelson, X. J. (2012a) Effects of introducing threatened falcons into vineyards on abundance of Passeriformes and bird damage to grapes. Conserv. Biol. 26: 142-149.

Kross, S. M., Tylianakis, J. M. and Nelson, X. J. $(2012 \mathrm{~b})$ Effects of translocation into vineyard habitat on the breeding behaviour of threatened New Zealand Falcons. PLoS ONE 7: e38679. doi:10.1371/journal.pone. 0038679

Lewis, R. M., Armstrong, D. P., Joy, M. K., Richard, Y., Ravine, D., Berggren, A. and Boulton, R. L. (2009) Using artificial nests to predict nest survival at reintroduction sites. N.Z. J. Ecol. 33: 40-51.

MacLeod, C. J., Blackwell, G., Moller, H., Innes, J. and Powlesland, R. (2008) The forgotten $60 \%$ : bird ecology and management in New Zealand's agricultural landscape. New Zeal. J. Ecol. 32: 240-255.

MAF (2009) SFF project summary - Falcons for grapes: A project to conserve falcons and protect grapes in Marlborough. Auckland, Ministry of Agriculture and Forestry. Available http://www.maf.govt. $\mathrm{nz} /$ environment-natural-resources/fundingprogrammes/sustainable-farming-fund/ sustainable-farming-fund-search.aspx Accessed 20/I2/I1.

Major, R. E. and Kendal, C. E. (1996) The contribution of artificial nest experiments to understanding avian reproductive success: a review of methods and conclusions. Ibis 138: 298-307.

Margules, C. R. and Pressey, R. L. (2000) Systematic conservation planning. Nature 405: 243-253.

McDonald, P. G., Kazem, A. J. N. and Wright, J. (2007) A critical analysis of 'false-feeding' behavior in a cooperatively breeding bird: disturbance effects, satiated nestlings or deception?Behav. Ecol. Sociobiol. 61: $1623-1635$. 
McDonald, P. G., Wilson, D. R. and Evans, C. S. (2009) Nestling begging increases predation risk, regardless of spectral characteristics or avian mobbing. Behav. Ecol. 20: 821-829.

McLennan, J. A., Potter, M. A., Robertson, H. A., Wake, G. C., Colbourne, R., Dew, L., Joyce, L., McCann, A. J., Miles, J., Miller, P. J. and Reid, J. (1996) Role of predation in the decline of kiwi, Apteryx spp., in New Zealand. N.Z. J. Ecol. 20: 27-35.

Medina, F. M., Bonnaud, E., Vidal, E., Tershy, B. R., Zavaleta, E. S., Donlan, C. J., Keitt, B. S., Le Corre, M., Horwath, S. V. and Nogales, M. (2011) A global review of the impacts of invasive cats on island endangered vertebrates. Global Change Biol. 17: 3503-3510.

Miskelly, C. M., Dowding, J. E., Elliot, G. P., Hitchmough, R. A., Powlesland, R. G., Robertson, H. A., Sagar, P. M., Scofield, R. P. and Taylor, G. A. (2008) Conservation status of New Zealand birds. Notornis 55: 117-135.

Moore, R. P. and Robinson, W. D. (2004) Artificial bird nests, external validity, and bias in ecological field studies. Ecology 85 : 1562-1567.

Newton, I. (1979) Population ecology of raptors, Berkhamsted, UK: T \& AD Poyser.

Pietz, P. J. and Granfors, D. A. (200o) Identifying predators and fates of grassland passerine nests using miniature video cameras. J. Wildlife Manage. 64: 71-87.

Ratcliffe, D. A. (1967) Decrease in eggshell weight in certain birds of prey. Nature 215: 208-210.
Sanders, M. D. and Maloney, R. F. (2002) Causes of mortality at nests of ground-nesting birds in the Upper Waitaki Basin, South Island, New Zealand: a 5-year video study. Biol. Conserv. 106: 225-236.

Seaton, R., Holland, J. D., Minot, E. O. and Springett, B. P. (2009) Breeding success of New Zealand Falcons (Falco novaeseelandiae) in pine plantation. New Zeal. J. Ecol. 33: 32-39.

Smith, D. H. V., Wilson, D. J., Moller, H. and Murphy, E. C. (2008) Using artificial nests to explore predation by introduced predators inhabiting alpine areas in New Zealand. New Zeal. J. Zool. 35: 119-128.

Steenhof, K. and Newton, I. (2007) Assessing nesting success and productivity. In: Bird, D. M. and Bildstein, K. L., eds. Raptor research and management techniques. Surrey, BC and Blaine, WA: Hancock House.

Towns, D. R., Atkinson, I. A. E. and Daugherty, C. H. (2006) Have the harmful effects of introduced rats on islands been exaggerated? Biol. Invasions 8: 863-891.

Vander Haegen, W. M., Schroeder, M. A. and Degraaf, R. M. (2002) Predation on real and artificial nests in shrubsteppe landscapes fragmented by agriculture. Condor 104: 496-506.

Whitehead, A. L., Edge, K. A., Smart, A. F., Hill, G. S. and Willans, M. J. (2008) Large scale predator control improves the productivity of a rare New Zealand riverine duck. Biol. Conserv. 141: 2784-2794.

Wilson, G. R., Brittingham, M. C. and Goodrich, L. J. (1998) How well do artificial nests estimate success of real nests? Condor 100: 357-364.

\section{SARA M. KROSS*, XIMENA J. NELSON}

School of Biological Sciences, University of Canterbury, Private Bag 4800, Christchurch, New Zealand.

PAUL G. McDONALD

Behavioural and Physiological Ecology Research Centre, Zoology, University of New England, Armidale, Australia 2351.

*Author for correspondence; email: saramaekross@gmail.com

Received 12 April 2012; revision accepted 20 August 2012; Published online 10 April 2013 